\title{
IMPLEMENTASI PENDEKATAN PENDIDIKAN MULTIKULTURAL KONTEKSTUAL BERBASIS KEARIFAN LOKAL DI INDONESIA
}

\author{
Tatang M. Amirin \\ Fakultas Ilmu Pendidikan Unversitas Negeri Yogyakarta
}

\begin{abstract}
Abstrak
Tujuan utama penerapan pendekatan pendidikan multikultural di tingkat nasional hendaknya dititikberatkan pada pemahaman dan penghargaan peserta didik terhadap budayanya sendiri dan budaya orang lain, mencakup agama, berlandaskan semboyan bhinneka tunggal ika serta Pancasila. Untuk itu maka diperlukan adanya penataan ulang dan penguatan pendidikan kewarganegaraan (PKn), IPS, dan pendidikan agama dengan memasukkan muatan materi keanekaragaman nilai-budaya, didukung oleh penelitian sosiologis dan antropologis untuk pendidikan. Di tingkat daerah atau lokal, pendekatan pendidikan multikultural seyogyanya diterapkan secara kontekstual, dengan menggunakan "kearifan lokal" membangun pemahaman dan saling menghargai perbedaan nilai budaya dan asal-usul etnisitas dan atau suku bangsa sesuai dengan keadaan setempat. Penelitian mengenai perbedaan nilai budaya setempat seyogyanya dilakukan oleh para pejabat pendidikan setempat dan guru dan atau pengajar universitas untuk dapat digunakan secara bijak dalam pengembangan struktur dan kultur sekolah dan kegiatan belajar-mengajar dan bimbingan di dalamnya.
\end{abstract}

Kata kunci: gerakan pendidikan multikultural; pendekatan pendidikan multikultural; ras; etnis; subetnis; kesetaraan jender; disabilitas; kultur dan subkultur di Indonesia; kearifan lokal; penelitian sosiologis-antropologis untuk pendidikan

\section{CONTEXTUAL IMPLEMENTATION OF MULTICULTURAL EDUCATION APPROACH BASED ON LOCAL WISDOM IN INDONESIA}

\begin{abstract}
In national level, multicultural education approach should be focused on developing student's understanding and appreciation of their own cultures and the culture of others, including religion, based on "bhinneka tunggal ika" ("unity in diversity") and Pancasila principles. Restructuring and strengthening citizenship education (PKn), social studies, and religious education should be done, supported by sociological and anthropological researches on multicultural values for educational purpose. In the regional and local level, multicultural education approach should be implemented contexctually, using local wisdom to develope mutual understanding and appreciation of ethnical or subethnical origin and or cultural diversity relevant to the local conditions. Research on local value diversity should be conducted by local school administrators and teachers and/or university faculties, and implemented wisely in developing school structures and cultures and in teaching-learning processes and guidances.
\end{abstract}

Keywords: multicultural education movement; multicultural education approach; ras; ethnic; subethnic; gender; disability; Indonesian culture and subculture; local wisdom; sosiologicalanthropological research for education 


\section{PENDAHULUAN}

Manakala orang mendengar istilah pendidikan multikultural, tanpa tahu asalmuasalnya, bisa saja lalu terjebak pada mencaricari rumusan kultur itu apa, dan multikultur itu apa, lalu pendidikan multikultur disimpulkan daripadanya. Dengan kata lain, disimpulkanlah bahwa pendidikan multikultur itu seabgai upaya mengajarkan beragam macam kultur Indonesia: Jawa, Sunda, Minangkabau, Batak, Ambon, Sasak, Baduy (Kanekes) dan sebagainya. Dan karena isi budaya itu antara lain kesenian, pakaian, rumah dan sebagainya, maka seperti pada pelajaran IPS, pada "pelajaran” multikultur itu diajarkanlah macam-macam alat musik daerah, tarian daerah, pakaian daerah, rumah adat daerah dan sebagainya.

Sudah barang tentu, walau ada sisi benarnya, pemikiran tersebut menjadi jauh panggang dari api, jauh bayang dari hakiki. Pendidikan multikultural itu awalnya merupakan gerakan reformasi pendidikan di Amerika Serikat dalam rangka meniadakan (setidaknya mengurangi) diskriminasi rasial dan etnis serta kultur yang melekat padanya, dan berupaya agar semua orang bisa memperoleh kesempatan yang setara untuk mendapatkan pendidikan. Diskriminasi rasial, etnisitas, dan kultural, bahkan jender sangat kental di Amerika Serikat, hingga saat ini.

Kultur dan subkultur serta etnis dan subetnis (suku bangsa) Indonesia berbeda secara signifikan dengan etnis dan kultur Amerika Serikat, dan sejarah perkembangannya pun berbeda. Oleh karenanya, maka untuk mengimplementasikan pendidikan multikultural di Indonesia memerlukan pengkajian yang cermat dengan melihat realita kehidupan bangsa, masyarakat, dan budaya Indonesia. Ada prinsipprinsip umum yang bisa diadopsi dari gerakan pendidikan multikultural Amerika Seriakt, tetapi ada yang tidak perlu menjadi bahan perhatian pendidikan Indonesia. Perbedaan kultur Indonesia dari Amerika Serikat, perbedaan sejarah budaya dan etnisitas Indonesia dari Amerika Serikat, dan bagaimana pendekatan pendidikan multikultural yang tepat dilakukan di Indonesia, itulah yang akan menjadi kajian tulisan ini.

\section{Sejarah Kelahiran dan Tujuan Pendidikan Multikultural di Amerika Serikat}

Pertama-tama dan terutama, pendidikan multikultural, yang mencuat di Amerika Serikat sekitar tahun 1960-an, itu merupakan suatu gerakan reformasi yang ditujukan pada perubahan pendidikan yang selama ini melakukan tindak diskriminasi terhadap masyarakat "minoritas," yaitu masyarakat yang berada di luar "white-male-Protestant-Anglo Saxon (WMPA)."

Multicultural education is a reform designed to make some major changes in the education of students. Multicultural education theorists and researchers believe that many school, college, and university practices related to race and ethnicity are harmful to students and reinforce many of the ethnic stereotype and discriminatory practices in U.S. society (Banks, 2002:1).

Gerakan pendidikan multikultural itu adalah gerakan untuk mereformasi lembagalembaga pendidikan agar memberikan peluang yang sama kepada setiap orang, tanpa melihat asal-usul etnis, budaya, dan jenis kelaminnya, untuk sama-sama memperoleh pengetahuan, kecakapan (skills), dan sikap yang diperlukan untuk bisa berfungsi secara efektif dalam negara-bangsa dan masyarakat dunia yang 
beragam etnis dan budaya (Banks, 2002:5; mengutip Banks, 2001; Banks \& Banks, 1995; Gay, 1995; dan Grant and Sleeter, 2001).

Menghilangkan diskriminasi sebagai salah satu tujuan utama gerakan pendidikan multikultural itu dengan tegas dinyatakan Banks seperti dalam nukilan berikut. Latar belakangnya adalah adanya pengalaman pahit kelompok-kelompok etnis Afro-Amerika, Pribumi Amerika, Asia-Amerika, dan LatinoAmerika yang pernah dan masih sedang menjadi korban diskriminasi, bukan saja dalam kehidupan kemasyarakatan, melainkan juga secara legal kelembagaan (dalam undangundang pun terdiskriminasikan).

Another major goal of multicultural education is to reduce the pain and discrimination that members of some ethnic and racial groups experience because of their unique racial, physical, and cultural characteristics (Banks, 2002: 4).

Groups such as African Americans, Native Americans, Asian Americans, and Latinos Americans have been historically — and are today-victims of institutional racisms in the United States. However, racism today is much more subtle and less blatant than it was prior to the Civil Rights Movement of the 1960s and 1970s (Banks, 2001:58; mengutip Cose, 1993; Feagin \& Sikes, 1994).

Kuatnya diskriminasi di Amerika Serikat itu digambarkan Banks dengan menegaskan bahwa betapa sulitnya orang kulit berwarna di Amerika Serikat mendapatkan kesetaraan hukum, sosial, dan politik sebagai warga negara Amerika Serikat. Mereka bisa secara hukum tersisihkan sebagai (untuk menjadi) warga negara, atau, jika secara hukum sudah tak masalah, untuk mendapatkan pendidikan tersisihkan juga, dan jika secara akademik tak masalah, dalam kenyataan hidup masih terganjal juga oleh diskriminasi rasial.

Groups of color have experienced three major problems in becoming citizens of the United States. First, they were denied legal citizenship by laws. Second, when legal barriers to citizenship were eliminated, they were often denied educational experiences that would enable them to attain the cultural and language characteristics needed to function effectively in the mainstream society. Third, they were often denied the opportunity to fully participate in mainstream society even when they attained these characteristics because of racial discrimination (Banks, 2007: xi).

Mengenai tujuan gerakan pendidikan multikultural itu, Banks (2002:1-4) merumuskan ada empat. Pertama (dan terutama), membantu individu memahami diri sendiri secara mendalam dengan mengaca diri dari kaca mata budaya lain ("to help individuals gain greater self-understanding by viewing themselves from the perspectives of other cultures"). Kedua, membekali peserta didik pengetahuan mengenai etnis dan budaya-budaya lain, budayanya sendiri dalam budaya "mayoritas," dan lintas budaya ("to provide students with cultural and ethnic alternatives"), karena selama ini mereka hanya "dicekoki" sejarah dan budaya "dominan," yaitu sejarah dan budaya Anglo-Amerika. Ketiga, mengurangi derita dan diskriminasi ras, warna kulit, dan budaya ("to reduce the pain and discrimination that members of some ethnic groups experience because of their unique racial, physical, and cultural characteristics"). Keempat, membantu para peserta didik menguasai kemampuan dasar membaca, menulis dan berhitung ("to help students to master essential reading, writing, and math skills").

Sementara itu, Paul C. Gorski menjelaskan tujuan reformasi pendidikan lewat 
gerakan pendidikan multikultural itu untuk mengubah sistem pendidikan yang lebih berbasiskan keadilan sosial, keseteraan-keadilan pendidikan, pedagogi kritis, dan dedikasi, dalam rangka memberikan pengalaman pendidikan yang memungkinkan semua peserta didik mengembangkan sepenuh-penuhnya seluruh potensi dirinya, dan menjadi anggota masyarakat yang sadar sosial dan berperan aktif secara lokal, nasional, dan juga global.

Multicultural education is a progressive approach for transforming education that holistically critiques and responds to discriminatory policies and practices in education. It is grounded in ideals of social justice, education equity, critical pedagogy, and dedication to providing educational experiences in which all students reach their full potentials as learners and as socially aware and active beings, locally, nationally, and globally (Gorski: 2010).

Dengan kata lain, menurut Gorski, ada tiga tujuan utama pendidikan multikultural (yang boleh disebut sebagai sasaran instrumental dan terminal), yaitu:

(1) meniadakan diskriminasi pendidikan, memberi peluang sama bagi setiap anak untuk mengembangkan potensinya (tujuan instrumental);

(2) menjadikan anak bisa mencapai prestasi akademik sesuai potensinya (tujuan terminal internal);

(3) menjadikan anak sadar sosial dan aktif sebagai warga masyarakat lokal, nasional, dan global (tujuan terminal akhir eksternal).

\section{Perluasan Subjek Pendidikan Multikultural}

Dari paparan di muka telah diketahui bahwa subjek sasaran "pemicu" pendidikan multikultural itu pada mulanya, dan terutama, adalah "orang-orang normal" yang secara ras, etnis, dan budaya terdiskriminasikan (termarginalkan atau tersisihkan), walaupun prestasi akademik dan layanan pendidikan yang sesuai itu menyangkut semua juga, baik yang terdiskriminasikan, maupun yang tidak terdiskriminasikan. Khusus di Amerika Serikat, karena yang dominan adalah kultur White Male Protestant Anglo Saxon yang disingkat WMPA (Zamroni, 2011a:141), maka otomatis kaum perempuan termasuk yang terdiskriminasi atau terpinggirkan. Jadi, selain kelompok etnis dan budaya "minoritas" (tidak harus selalu berarti jumlahnya lebih sedikit dari WMPA), perempuan pun termasuk yang terdiskriminasi.

Oleh karena adanya diskriminasi memperoleh pendidikan, maka warga kelompok etnis dan budaya "berbeda dari WMPA" tidak mudah untuk mendapatkan pekerjaan yang baik, dan karenanya tidak bisa mendapatkan penghasilan yang layak, sehingga mereka termasuk kaum miskin. Selain itu, dalam hal pekerjaan pun mereka termasuk terdiskriminasi. "Warga kelompok minoritas sulit mendapatkan pekerjaan, dan ada kebijakan diskriminatif yang jelas." (Zamroni, 2011a:141). Bahkan, kaum perempuan mendapatkan penghasilan yang jauh di bawah laki-laki, walau jenis pekerjaan yang dikerjakannya sama (Zamroni, 2011a: 141).

Subjek sasaran pendidikan multikultural itu berkembang lagi menjadi memasukkan kelompok orang-orang penyandang cacat atau "disabel."

... the term multicultural education (now) describes a wide variety of programs and practices related to educational equity, women, ethnic groups, language minorities, low-income groups, and people with disabilities (Banks \& Banks, 2001; dalam Zamroni, 2011a:140). 
Perlu dicatat bahwa dalam nukilan di atas disebutkan bahwa subjek sasaran pendidikan multicultural dalam rangka memperoleh kesetaraan pendidikan itu adalah: (1) kaum perempuan, (2) kelompok etnis, (3) kelompok minoritas kebahasaan, (4) kelompok berpendapatan rendah, dan (5) penyandang kecacatan. Seperti telah disinggung di muka, kelompok berpendapatan rendah miskin karena etnis atau rasnya terdiskriminasikan. Bahasa (tidak mampu berbahasa Inggris yang dijadikan pengantar pengajaran di sekolah), juga terkait asal-usulnya yang etnis non-bahasa Inggeris. Sementara itu, kecacatan merupakan sesuatu yang khusus, karena tidak terkait dengan etnisitas, walaupun, karena status ekonomi kelompok minoritas itu rendah, penyandang cacat itu banyak dari kalangan minoritas.

A significant segment of the population in the United States is made up of exceptional individuals. Twenty-five million or more individuals from every ethnic and socioeconomic group fall into one or more of the categories of exceptionality. Nearly every day, educators come into contact with exceptional children and adults (Gollnick \& Chinn, 2006:178).

Bagaimana di Indonesia, haruskah mereka yang cacat (disable) itu dimasukkan ke dalam "kajian" pendidikan multikultural, itu yang akan dibahas di bawah. Terlebih dahulu akan dibahas secara umum prinsip dasar bagaimana seyogyanya pendidikan multikultural diimplementasikan di Indonesia.

\section{Prinsip Dasar Implementasi Pendidikan Multikultural di Indonesia}

Telah disebutkan di muka bahwa pendidikan multikultural itu pada awalnya merupakan gerakan reformasi pendidikan (di A.S.) karena adanya diskriminasi etnis dan kultur oleh etnis dan kultur "mayoritas" WMPA. Oleh karena itu, maka untuk menerapkan pendidikan multikultural di Indonesia haruslah hati-hati, tepat, dan bijaksana, karena belum tentu sama dengan Amerika.

Bagaimana pendidikan multikultural dapat diimplementasikan di negara lain di luar Amerika Serikat? Bagaimana mentransfer konsep pendidikan multikultural ala Amerika Serikat menjadi model yang sesuai dengan kondisi dan kebutuhan bangsa Indonesia? Sudah barang tentu perlu penyesuaian dan pemahaman yang benar. (Zamroni, 2011a:159; cetak tebal dari Penulis).

Dengan kata lain, jika pendekatan pendidikan multikultural akan diimplementasikan di Indonesia, haruslah berdasarkan realita Indonesia dan kearifan lokal (local wisdom atau indigenous knowledge) dalam makna luas, tegasnya dengan memperhatikan karakteristik bangsa dan budaya Indonesia sendiri.

Local wisdom is defined as what mankind using his brain powers to act and behave toward things, objects, or events that occur in a particular space, also a pattern of relationship between human interaction with humans or humans with their physical environment

(shareforearth.blogspot.com/2011/01).

Indigenous knowledge (IK) is the local knowledge - knowledge that is unique to a given culture or society. IK contrasts with the international knowledge system generated by universities, research institutions and private firms. It is the basis for local-level decision making in agriculture, health care, food preparation, education, natural-resource management, and a host of other activities in rural communities. (Warren 1991; cited on 12 January, 2012 from www.worldbank.org/afr/ik/basic.htm)

Indigenous Knowledge is (...) the information base for a society, which facilitates communication and decision- 
making. Indigenous information systems are dynamic, and are continually influenced by internal creativity and experimentation as well as by contact with external systems. (Flavier et al. 1995: 479; cited on 12 January, 2012 from www.worldbank.org/afr/ik/basic.htm)

Sebelum lanjut, dalam konteks implementasinya di Indonesia, pendidikan multilkultural itu dapat dilihat atau diposisikan sebagai berikut.

1. Sebagai falsafah pendidikan; yaitu pandangan bahwa kekayaan keberagaman budaya Indonesia hendaknya dimanfaatkan sebaik-baiknya untuk mengembangkan dan meningkatkan sistem pendidikan dan kegiatan belajar-mengajar di Indonesia guna mencapai masyarakat Indonesia yang adil dan makmur (berbarkat) dan bahagia dunia akhirat.

2. Sebagai pendekatan pendidikan; yaitu penyelenggaraan dan pelaksanaan pendidikan yang kontekstual, yang memperhatikan keragaman budaya Indonesia. Nilai budaya diyakini mempengaruhi pandangan, keyakinan, dan perilaku individu (pendidik dan peserta didik), dan akan terbawa ke dalam situasi pendidikan di sekolah dan pergaulan informal antar individu, serta mempengaruhi pula struktur pendidikan di sekolah (kurikulum, pedagogi dan faktor lainnya). Meminjam “teori” Zamroni (2011a:149-gambar), kedudukan nilai budaya dalam struktur statis pendidikan (bawaan siswa, bawaan guru, kurikulum, dan pedagogi atau "the art of teaching") akan tampak sebagai berikut.

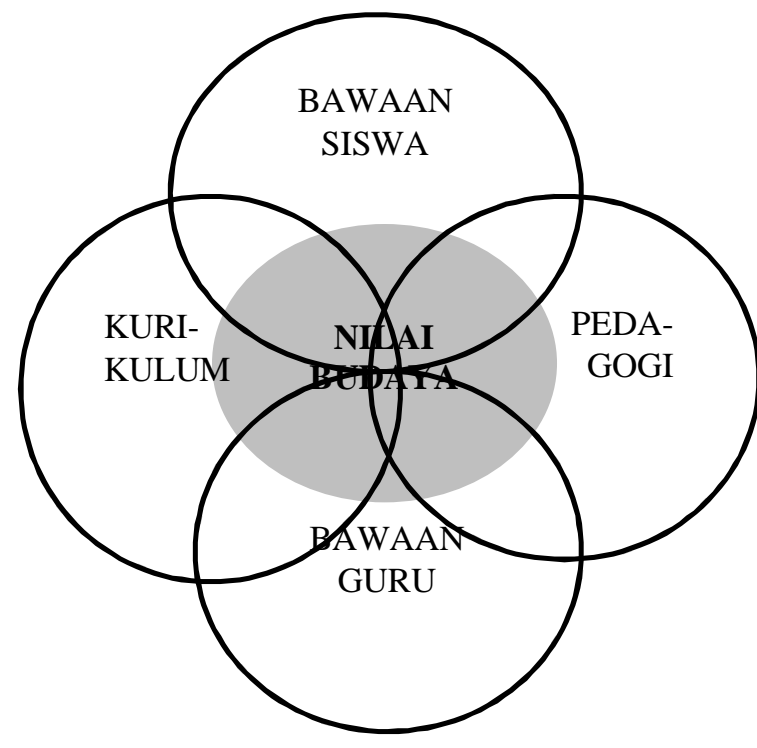

Gambar 1. Nilai Budaya dalam Struktur Pendidikan (Adaptasi dari Zamroni, 2011)

3. Bidang kajian dan bidang studi; yaitu disiplin ilmu yang-dibantu oleh sosiologi dan antropologi pendidikan-menelaah dan mengkaji aspek-aspek kebudayaan, terutama nilai-nilai budaya dan perwujudannya (norma, etiket atau tatakrama, adat-istiadat atau tradisi dan lain-lain-mencakup "manifestasi budaya" agama) untuk/dalam penyelenggaraan dan pelaksanaan pendidikan. Hasil telaah dan kajian ini akan dapat menjadi bidang studi yang diajarkan secara operasional (dan kontekstual) kepada para calon pendidik yang mungkin akan berhadapan dengan keragaman budaya (tidak harus untuk semua). Sebaliknya, "proses pendidikan yang multikultural" itu pun harus juga terus dikaji ditelaah, baik efektivitas dan efisiensinya, maupun-dan terutamakesesuaiannya dengan situasi dan kondisi Indonesia, dan ketepatan sesuai dengan hakekatnya.

Jadi, penulis memandang ada tiga status pendidikan multikultural (yang saling 
berhubungan secara fungsional) yang harus terus dikembangkan jika akan diimplementasikan di Indonesia—seusai dengan "kultur" Indonesia. Artinya, jika didudukkan sebagai falsafah pendidikan, maka harus dianalisis secara filosofis hakekatnya sebagai apa. Jika sebagai bidang kajian (disiplin ilmu dalam Ilmu Pendidikan) juga harus dipertegas dari sudut filsafat ilmunya. Jika dipandang sebagai pendekatan, maka harus jelas apa yang didekati dan bagaimana melakukan pendekatannya secara ilmiah, sesuai, dan benar.

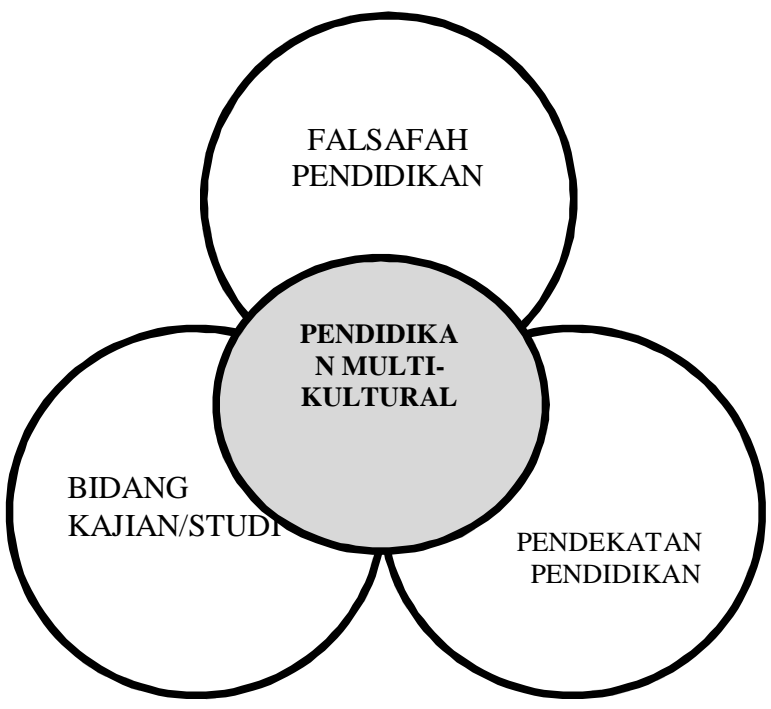

Gambar 2. Fungsi Pendidikan Multikultural

Penegasan mengenai "apa" pendidikan multikultural itu penting agar dalam pembicaraan mengenai pengimplementasiannya di Indonesia sudut pandangnya sama. Tanpa kesepahaman, maka pembicaraan mengenainya akan tidak sejalan. Dalam hal ini Penulis akan lebih banyak menekankannya sebagai

\section{pendekatan dalam penyelenggaraan dan pelaksanaan pendidikan.}

Pada paparan berikut akan dibahas satu per satu muatan atau aspek implementasi pendidikan multikultural di Indonesia, dengan pertama-tama mengenai karakteristik kultur dan multikultur Indonesia-mencakup etnis dan ras, selanjutnya mengenai diskriminasi rasial, etnisitas dan budaya, kemudian diskriminasi jender (kesetaraan pendidikan bagi kaum perempuan) dan anak berkebutuhan khusus (disable), karena hal-hal tersebut disinggungsinggung sebagai "bagian" dari pendidikan multikultural ala Amerika Serikat. Terakhir dibahas mengenai arti penting penelitian multikultur (keberagaman budaya) Indonesia untuk implementasi dan pengembangan pendekatan pendidikan multikultural ala Indonesia. Hal yang sangat teknis (strategi belajar-mengajar) tidak akan dibahas dalam tulisan ini. Mungkin pada kesempatan lain, karena pasti akan bisa panjang lebar.

\section{Karakteristik Multikultur Indonesia}

Yang pertama-tama harus dicermati dalam konteks implementasi pendidikan multikultural di Indonesia adalah seperti apakah kultur dan multikultur di Indonesia itu. Samakah dengan yang ada di Amerika Serikat? Bagaimana pula ciri-ciri khas etnis dan kebudayaan Indonesia jika dilihat dalam perbandingan dengan konteks pendidikan multikultural ala Amerika Serikat?

Pertama, kebudayaan Indonesia dari sisi yang statis, meminjam kategorisasi Parekh (1997; dalam Sunarto, Heng, dan Saifuddin, 2004:2-3) tentang "multikulturalisme," bukan kulturnya, dapat dikategorisasikan menjadi:

1. Isolated culture, kebudayaan yang hidup tersendiri tidak berinteraksi kuat dengan kebudayaan lainnya, sebagian karena batasbatas geografis;

2. Cosmopolitan multiculture, kebudayaan yang berbaur menjadi satu, kadang tanpa batas, sehingga "anggota kelompok" (etnis, 
subetnis atau suku-bangsa) sudah tidak terlampau peduli dengan kebudayaan dan nilai-nilainya sendiri;

3. Accommodative culture, kebudayaan yang ada di sesuatu daerah di mana ada kebudayaan "subetnis" yang dominan (diikuti mayoritas penduduk), tetapi ada juga kebudayaan subetnis lain, yang bisa hidup bersama tanpa pergesekan apapun, dan tanpa ada "diskriminasi" apapun.

Kebudayaan tipe pertama, kebudayaan yang terisolasi (karena geografis, menjadi kedaerahan) paling banyak terdapat di Indonesia, karena penduduk tidak asli daerah yang berpindah ke derah tersebut pun relatif sedikit, dan kadang menjadi isolated juga karena terkonsentrasi di derah tertentu (pemukiman trans, misalnya). Kebudayaan tipe kedua terdapat di berbagai kota besar di Indonesia karena penduduknya campur baur dari beragam suku-bangsa dan etnis/subetnis. Kebudayaan tipe ketiga terutama terdapat di pulau Jawa karena banyak suku bangsa dan penduduk dengan asal-usul etnis yang tinggal menetap sebagai penduduk "asli" dari hasil perkawinan, pendidikan, pekerjaan dan sebagainya. Ini tidak menutup diri dari bahwa kebudayaan daerah pun bersifat akomodatif.

Kedua, dari sisi yang dinamis, sejak proklamasi kemerdekaan yang didahului oleh Sumpah Pemuda telah terikrarkan dari sanubari seluruh bangsa Indonesia bahwa bangsa Indonesia itu "satu nusa, satu bangsa, dan satu bahasa persatuan nasional." Kesatubangsaan itu benar-benar mencakup seluruh orang Indonesia, dari mana pun asalnya. Sebagai perbandingan, Sumpah Pemuda Indonesia itu jauh berbeda nuansanya dengan Konstitusi Amerika Serikat.
Sebutan "pemuda" dalam sumpah itu benarbenar menunjukkan semua pemuda Indonesia. Ini berbeda dengan "we the people"-nya Konstitusi Amerika Serikat seperti dinyatakan Banks (2007:1) berikut.

Educating students for effective citizenship has been a problem in the United States since the nation's beginning because of the way in which the Founding Fathers defined "We the people" in the Constitution. "We the people" referred to White males who were property owners. African Americans, Native Americans, women from all racial and ethnic groups, and White males without property were denied the privileges of citizenship in the commonwealth (cetak tebal dri Penulis).

Sumpah Pemuda Indonesia itu mencerminkan seluruh pemuda Indonesia, bahkan seluruh rakyat Indonesia, lewat perjalanan sejarah, bukan pemuda atau rakyat Indonesia tertentu saja. Bunyi Sumpah Pemuda itu selengkapnya (masih dalam ejaan lama) sebagai berikut.

Pertama

Kami poetera dan poeteri Indonesia, mengakoe bertoempah darah jang satoe, tanah Indonesia.

Kedoea

Kami poetera dan poeteri Indonesia, mengakoe berbangsa jang satoe, bangsa Indonesia.

Ketiga

Kami poetera dan poeteri Indonesia, mendjoendjoeng bahasa persatoean, bahasa Indonesia.

Di Indonesia, etnis selain etnis Indonesia relatif kecil jumlahnya, dan jika ada konsentrasi, hanya di beberapa wilayah tertentu saja. Pembedaan etnis itu pun sebenarnya lebih hanya sebagai warisan penjajahan Belanda yang secara sengaja diskriminatif untuk keperluan politisnya. Itulah sebabnya di Indonesia lebih dikenal adanya multisubetnis yang disebut sukubangsa daripada multietnis. Suku bangsa itu pun 
tidak terlampau mencolok "perlakuannya" dilihat dari ras, lebih dilhat dari budaya dan bahasanya. Itupun kerap sudah membaur karena perkawinan. Ada perbedaan ras, memang, tetapi tidak pernah ada perlakuan khusus terkait dengan ras, perlakuan lebih pada daerahnya, sehingga tetap disebut sukubangsa dari bangsa Indonesia.

Oleh karena tidak ada etnis berbeda yang besar-besar, maka di Indonesia juga tidak dikenal multikultur berbasis etnis, yang ada sebenarnya subkultur. Semuanya, kendati dalam keanekaragaman atau bhinneka, merupakan budaya Indonesia. Jadi, budaya Sunda (punya Penulis) dan budaya Jawa (punya istri Penulis), sebagai misal, semuanya budaya Indonesia. Bahkan budaya Cina dan Arab pun, yang ada di Indonesia, diakui sebagai budaya Indonesia. Qasidah atau nasyid yang asalnya dari Arab, lazim dianggap budaya kelompok Muslim Indonesia. Permainan liong dan barongsay, ketika Penulis masih kecil, ditampilkan di desa (bukan di kota), yang tidak ada warga asal Cina seorang pun, oleh "suku Sunda" dengan tanpa kikuk (rikuh-Jawa) dalam perayaan 17 Agustusan.

Yang lebih sensitif di Indonesia sebenarnya multireligi, bukan multikultur. Benturan antar pemeluk agama, bahkan antar penganut mazhab, aliran, atau sekte dalam satu agama pun bisa terjadi. Faktornya bisa beragam, sebagian kadang karena dimomoti kepentingan politik, sebagian karena faktor in group dan out group yang terlampau kental. Dalam keadaan normal, lazimnya tidak terlampau terlihat adanya diskriminasi religius, atau konflik antar religi (antar subreligi). Semua pemeluk agama di Indonesia bisa hidup berdampingan tanpa halangan. Jika ada konflik, pasti ada pemicu lain yang turut berperan. Pemeluk Islam "fundamentalis" yang suka dikatakan "ekstrimis" itu pun, sebagian perilakunya ada unsur politis di dalamnya. Oleh karena itulah maka ada "bom Cirebon," bom orang Islam terhadap orang Islam sendiri.

Konflik agama yang lazim muncul adalah karena adanya anggapan penodaan kesucian agama, misalnya oleh aliran-aliran kepercayaan yang mengatasnamakan agama Islam, tetapi sebenarnya jauh menyimpang dari ajaran Islam. Ini bukan soal toleransi keberagamaan, ini sudah soal hukum. Keberagamaan (religiusitas) di Indonesia juga pada dasarnya akomodatif, terutama terkait dengan "tradisi budayanya." Lebaran, sebagai contoh, tidak hanya "dirayakan" oleh umat Islam, umat yang lain pun ikut "merayakannya" dengan caranya sendiri-sendiri. Tahun baru Masehi dirayakan pula oleh anak-anak muda Islam.

\section{Diskriminasi Etnis dan Kultur di Indonesia}

Seperti telah disebutkan di muka, kultur Indonesia itu sebagian besar merupakan isolated culture yang jarang bersentuhan apalagi "bersinggungan" dengan budaya lain, sehingga konflik budaya sangat amat jarang terjadi, seperti juga konflik etnis. Jika ada konflik etnis, sebenarnya bukan karena etnisitasnya, melainkan karena ada faktor lain (sengketa tanah, politik, persoalan pribadi, dan sebagainya).

Kultur lain yang "dominan" di Indonesia adalah accommodative culture, budaya yang sangat akomodatif. Di Indonesia dapat dikatakan bahwa kultur (subkultur) yang dominan adalah kultur Jawa. Akan tetapi, berbeda dengan di Amerika Serikat, budaya Jawa tidak 
mendominasi budaya lainnya. "Kalau kultur Jawa menindas kultur yang lain, tidak akan mungkin bahasa Indonesia menjadi bahasa nasional" (Zamroni, 2011a:160). Ini amat sangat berbeda dengan di Amerika Serikat.

Extending from the 1990s, the great civil rights movement was a continuation of the culture wars inititated by English colonist when they invaded Native American lands in North America. From the time of the invation to the 1990s, many citizens tried to assure that Protestant Anglo-American culture would be the dominant culture of the United States. For instance, in the 1990s, historian Arthur Schlesinger, who opposed multicultural education in public schools and advocated the teaching of Protestant Anglo-American culture, wrote, "For better or worse, the white AngloSaxon Protestant tradition was for two centuries-and in crucial respects still isthe dominant influencing on American culture and society. (Schlesinger, 1991:8; cited by Spring in Noel (Ed.), 2000:11-12).

Sifat akomodatif kultur (subkultur) di Indonesia itu, bisa pula dilihat bukan hanya dari kultur dan bahasa Jawa. Lagu-lagu puitis Sunda "buhun" (klasik) sebagian mengadopsi pola Jawa (pengaruh Mataram yang pernah menguasai Sunda), sehingga, walau tetap berbahasa Sunda (identitas budaya setempat), lagunya dan namanya mengikuti "pupuh-pupuh" (patokan) dan nama Jawa tapi dengan "logat" Sunda, yaitu Maskumambang, Mijil, Kinanti, Asmarandana, Dangdanggula, Magatruh, Pucung dan sebagainya. Bahkan aksara Jawa "ajisakan" diadopsi menjadi aksara Sunda "cacarakan" dengan penyesuaian atau pengurangan abjad (dituliskan dalam tanda kurung), yaitu: ha-na-ca-ra-ka (ada utusan); data-sa-wa-la (para duta atau utusan itu bersilangsengketa); pa-[dha]-ja-ya-nya (lalu perang tanding, sama-sama digjayanya), ma-ga-ba[tha]-nga (karena sama-sama digjaya itu, semua menjadi "bathang"-Jawa, babatangSunda; artinya mayat). Cara mengurutkan "abjad" tersebut sangat didaktis, yaitu menggunakan teori psikologi Gestalt dan pendekatan "meaningful learning"--yang saat itu tentu sama sekali belum dikenal, tapi justru sudah dikuasai. Dua baris terakhir itu yang di Sunda diubah, karena tuturan Sunda tidak mengenal "dha" dan "tha".

Jadi, dapatlah disimpulkan bahwa di Indonesia tidak pernah ada diskriminasi rasial, etnis, atau kultur, sehingga, jika pendidikan multikultural akan diimplementasikan di Indonesia, sama sekali tidak dimaksudkan untuk mengatasi diskriminasi rasial, etnis, atau kultural, atau mengandung muatan kesetaraan antar ras, etnis, dan kultur, karena tidak diperlukan. Oleh karena itu pula tidak mencuat adanya "race or ethnic prejudice" (prasangka kelompok berbasis ras atau etnis). Jika tampak seperti itu, sebenarnya akarnya bukan pada ras, etnis, atau kulturnya, melainkan pada orangorang tertentu dengan sebab politis, kesenjangan ekonomi, dan lain-lain.

\section{Kesetaraan Jender dan Disabilitas}

Kesetaraan jender. Salah satu bentuk diskriminasi "kultural" di Amerika Serikat adalah diskriminasi jender. Ini bisa dimaklumi karena dengan tegas "kultur" yang dominan dan mendominasi Amerika Serikat itu adalah "kultur" dari kelompok "white" (kulit putih), itu pun hanya "male" (lelaki), itu pun yang beragama Protestan, dan itu pun yang etnisnya Anglo-Saxon (WMPA). Kaum perempuan dipinggirkan dan ditidakadili. Seperti telah disebutkan di muka, bahkan kaum perempuan mendapatkan penghasilan yang jauh di bawah 
laki-laki, walau jenis pekerjaan yang dikerjakannya sama (Zamroni, 2011a:141).

Diskriminasi pendidikan bagi kaum perempuan di Indonesia pernah terjadi, tapi itu dahulu, di jaman penjajahan Belanda. Semenjak Kartini, Dewi Sartika dan lain-lain bergerak, maka pendidikan bagi kaum perempuan Indonesia sama sekali tidak diskriminatif. Jauh sebelum kemerdekaan Indonesia diproklamasikan, pendidikan bagi kaum wanita sudah diperhatikan.

Sejak Taman Siswa di Yogyakarta mengadakan Wisma-Rini, maka sudah dimulai dengan membuat pandangan dan merencanakan daftar pekerjaan berhubung dengan pengajaran dan pendidikan anakanak gadis. (Ki Hadjar Dewantara, "Wasita" Jilid 1 No.3 - Desember 1928; dalam Majlis Luhur Persatuan Taman siswa, 1977:8).
Kesetaraan kesempatan memperoleh pendidikan bagi perempuan di Indonesia sudah tidak lagi menjadi masalah. Bahkan, dalam beberapa kasus, bukan saja kesempatan memperoleh pendidikan tinggi terbuka sangat amat lebar, melainkan perempuan lebih berprestsi dibandingkan laki-laki. Sebagai gambaran (sengaja diambilkan tahun yang agak lampau), lulusan (wisudawan) cumlaude Universitas Negeri Yogyakarta jenjang S3, S2, S1 dan Diploma 3 dalam tiga periode wisuda berikut, persentase perempuannya jauh lebih tinggi. Kalau toh ada yang "minor" berdalih karena jumlah mahasiswa perempuan lebih banyak-itu tetap tidak mengubah kenyataan bahwa tidak ada diskriminasi jender dalam pendidikan di Indonesia.

Tabel 1. Perbandingan Wisudawan Cumlaude UNY Laki-laki dan Perempuan

\begin{tabular}{|l|c|c|c|}
\hline \multicolumn{1}{|c|}{ Periode } & Laki-laki & Perempuan & Jumlah \\
\hline 3 Juni 2006 & 13 & $\begin{array}{c}25 \\
(66 \%)\end{array}$ & $\begin{array}{c}38 \\
(100 \%)\end{array}$ \\
\hline 16 Desember 2006 & $(33 \%)$ & 42 & 54 \\
& $(22 \%)$ & $(78 \%)$ & $(100 \%)$ \\
\hline 13-14 Desember 2007 & 23 & 94 & 117 \\
& $(20 \%)$ & $(80 \%)$ & $(100 \%)$ \\
\hline
\end{tabular}

Dalam hal kesetaraan jender di bidang lain (pekerjaan, politik, dan sebagainya) diskriminasi juga tidak tidak terlampau kelihatan. Tentu ada sisi-sisi ajaran agama Islam yang dalam keyakinan pihak tertentu perempuan tidak diizinkan menjadi pemimpin. Tapi, itu khilafiyah, dan tidak berlaku "umum." Nyatanya, tidak banyak yang menolak Megawati menjadi Presiden. Ihwal keterwakilan perempuan di legislatif yang tidak sebanding dengan jumlah perempuan, persoalannya belum tentu terletak pada diskriminasi, melainkan pada (1) tergantung seberapa banyak perempuan yang mampu berpolitik, dan (2) tergantung seberapa banyak perempuan yang bersedia berpolitik. Terlampau naiff jika dikaitkan dengan diskriminasi jender.

Salah satu yang Penulis tidak sependapat adalah kritikan jenderis mengenai isi bacaan anak-anak yang konon diskriminatif jender. Selalu akan muncul, katanya "ibu memasak di dapur," seolah-olah ibu tidak bisa berperan lain. 
Persoalannya, sekali lagi, bukan pada diskriminasi jender, melainkan pada anak tidak boleh dibawa ke "alam lain” yang mereka tidak alami, yang tidak kontekstual. Ini setara dengan (menurut tuturan seorang dosen UGM Yogyakarta) ketika anaknya yang murid SD "digerutui" guru PKn karena ia "tidak membantu ayah dan ibu" sesuai "ajaran" PKn. Padahal, dalam "kepala si anak," ia memang tak mungkin dan tak mampu membantu ayah dan ibunya, karena ayahnya dosen dan ibunya manajer toko swalayan. Ia, yang murid SD, tak bisa menjadi asisten dosen atau staf ahli toko swalayan, tentu saja. Membantu membereskan tempat tidur seperti dalam nyanyian? Di rumahnya itu merupakan pekerjaan pembantu rumah tangga. Hanya salah paham tentang makna membantu orang tua.

\section{Kaum Disabel}

Anak-anak berkebutuhan khusus di Indonesia sudah memperoleh kesempatan mendapatkan pendidikan, walau belum semua bisa menikmatinya. Ini juga bukan persoalan diskriminasi atau penyisihan, melainkan banyak faktor, termasuk geografis ataupun sosialsekonomi. Berikut disajikan nukilan berita mengenai layanan pendidikan bagi anak berkebutuhan khusus (ABK), termasuk sekolah inklusif di Indonesia.

\section{ASB: 2.000 Anak Berkebutuhan Khusus Belum Sekolah}

Kamis, 11 Agustus 2011 16:53 WIB

REPUBLIKA.CO.ID, YOGYAKARTA Manajer Arbeiter Samariter Bund Sandrine Bohan, Jacquot mengatakan sekitar 2.000 anak berkebutuhan khusus di Daerah Istimewa Yogyakarta (DIY) belum mendapat pendidikan di sekolah, karena orang tua tidak mengizinkan anaknya bersekolah. "Kendala lainnya adalah lokasi sekolah jauh dari rumah sehingga orang tua tidak menyekolahkan anaknya yang berkebutuhan khusus," katanya saat bertemu Wakil Gubernur Daerah Istimewa Yogyakarta (DIY) Paku Alam IX di Yogyakarta, Kamis (11/8).

Semarang, CyberNews. Pemerintah provinsi Jateng akan memprioritaskan model pendidikan inklusi bagi anak berkebutuhan khusus (ABK) di pendidikan formal, menyusul masih tingginya jumlah $A B K$ di Jateng yang belum bisa tertampung di sekolah luar biasa (SLB). Dari seluruh ABK yang mencapai 35 ribu anak, hanya sekitar 14,28\% saja atau sekitar 5.000 anak yang tertampung di pendidikan SLB. Anggota Komisi E DPRD Jateng Moh Zen Adv mengungkapkan, dengan cakupan jumlah siswa ABK yang minim artinya masih ada 30 ribu lebih anak berkebutuhan khusus yang harus ditangani oleh pemerintah karena pendidikan yang layak menjadi hak setiap anak usia wajib belajar (wajar) 9 tahun. Poin penting mengenai model pendidikan inklusi tersebut menjadi salah satu sorotan dalam rancangan peraturan daerah (raperda) mengenai strategi dan penyelenggaraan pendidikan yang kini masih dalam pembahasan dewan. "Solusinya dengan model pendidikan inklusi masuk ke jalur formal ditempatkan di kelas khusus dengan perlakuan yang khusus pula. Kalau hanya menambah SLB rasanya masih tetap akan kesulitan sehingga rancangan perda ini salah satunya memprioritaskan $A B K$," ujar Moh Zen, Senin (7/11).

Jadi, jelaslah bahwa anak berkebutuhan khusus (disable) di Indonesia tidak ada kaitan sedikitpun dengan diskriminasi kultural. Penangannya sudah merupakan program pemerintah, dan pendidikan gurunya pun sudah ada lembaga yang memangani. Di berbagai "universitas kependidikan" ada program studi pendidikan luar biasa yang menangani itu.

\section{Arti Penting Penelitian Multikultur Indonesia untuk Pendidikan}

Sepeti telah disinggung di muka, selama ini jika berkaitan dengan perbedaan individual 
peserta didik tekanannya pada "bawaan dasar" dan "pengalaman ajar," pada bakat minat potensi dan pada apa yang sudah diketahui anak dari kegiatan belajarnya yang lampau (di sekolah ataupun di masyarakat). Satu sisi yang belum mendapatkan perhatian serius adalah nilai budaya yang dibawa anak dan guru ke sekolah (Lihat kembali gambar Zamroni yang dimodifikasi di muka). Kadang kala tidak disadari bahwa ada perbedaan "nilai" antara guru dan murid. Dulu, seorang ibu dosen menggerutui mahasiswi yang berjilbab, dianggap tak pantas mahasiswi berkerudung ke kampus. Sekian tahun kemudian, anak-anaknya yang mahasiswi semuanya mengenakan jilbab, seiring mode wanita berjilbab mulai ngetren, dan si ibu diam-diam saja. Dulu ada pejabat yang melarang staf dosen dan karyawatinya mengenakan celana panjang, harus mengenakan rok, karena dianggap tidak sopan, padahal karyawatinya merasa susah naik sepeda motor mengenakan rok, dan merasa pakai celana panjang pun sopan-sopan saja, asal tidak ketat.

Dengan kata lain, Indonesia masih kekurangan penelitian sosiologis dan antropologis untuk pendidikan (bukan sosiologi/antropologi pendidikan). Perhatian terhadap penelitian sosiologis/antropologis untuk pendidikan multikultur di Amerika Serikat relatif sudah banyak, sebagian di antaranya melihat dari sisi struktur pendidikan (guru, konselor, dan sebagainya - Zamroni, 2011b), sebagian sudah masuk ke isi ranah sosiologiosantropologis (Zamroni, 2010).

Mengapa penelitian sosiologis/ antropologis untuk pendidikan itu penting? Perhatikan hasil penelitian berikut (Berns, 2004:223).
Research indicates that children's learning styles may be related to their ethnic socialization, and teachers should respond accordingly (Banks, 2002). However, teachers often communicate in the style of their own culture. For example, researchers compared the time a teacher waited for a child respond to a question and the time the teacher waited before talking again for a Euro-American and a Navajo teacher of the same group of thirdgrade Navajo students (White \& Tharp, 1988). The Navajo teacher waited considerably longer than the EuroAmerican teacher after the child responded before talking again. What was perceived by the Euro-American teacher as a completed response was often intended by the child as a pause, which the EuroAmerican teacher had interrupted. For their part, native Hawaiian students preferred "negative" wait times, with the listener speaking without waiting for the speaker to finish (White \& Tharp, 1988). This is often interpreted by teachers from other ethnic groups as rude interruption, but in Hawaiian society, it demonstrates invelovement (Tharp, 1989).

Andai itu terjadi di Indonesia--untungnya ini di Amerika--tapi siapa tahu ada tatakrama berbeda juga di Indonesia, seperti telah dicontohkan di atas. Guru Navajo (suku Indian) dan guru Euro-Amerika ternyata berbeda cara berperilaku ketika menunggu jawaban anak Navajo sebelum melanjutkan percakapan. Guru Navajo menunggu lama ketika anak "selesai" menjawab sebelum berbicara lebih lanjut, sementara guru Euro-Amerika langsung bicara selesai anak menjawab. "Selesai menjawab" yang dianggap guru Euro-Amerika sudah selesai betul-betul itu, ternyata itu merupakan "jeda" pembicaraan anak Navajo, dan anak Navajo jadinya menganggap gurunya tidak sopan "memutus pembicaraannya." Anak Hawaii, lain lagi. Ia suka "menimbrungi" pembicaraan guru, walau guru belum "selesai" bicara. Ini dianggap tidak sopan oleh guru Euro-Amerika, karena 
memutus pembicaraan orang. Padahal, dalam budaya Hawaii, itu merupakan bentuk keterlibatan dalam pembicaraan (jadi, sebenarnya itu menunjukkan anak benar-benar perhatian pada pembicaraan gurunya!). Bisa jadi ada pimpinan rapat universitas atau fakultas yang "kaku" harus satu per satu rampung bicara, baru kemudian ditanggapi, sementara ada yang justru dialog langsung, selesai persoalan, satusatu. Sah-sah saja. Itu gaya memimpin rapat. Itu "nilai budaya minor".

Perhatikan pula lanjutan paparan Berns (2004:223) berikut.

Another variation related to ethnic socialization is behavior. For example, Euro-American children are usually taught to look directly at an adult when being spoken to, whereas many African American, Mexican American, and Asian American children are taught to lower their eyes-behavior that may be interpreted as disrespect.

"Lain ladang lain belalang, lain padang lain rumputnya." Itulah budaya, itulah tatakrama (etiket). Anak-anak Asia yang diajari sopan-santun untuk menundukkan kepala manakala sedang berbicara, terutama pada orang yang lebih tua, dianggap guru Amerika Eropa menyepelekannya, karena tidak melihat kepadanya yang sedang berbicara. Jika guru Asia berhadapan dengan murid Euro-Amerika yang menantap matanya, bisa-bisa murid EuroAmerika itu dianggap menantang berkelahi!

Nah, bisa jadi, ada orang yang mengajak bersalaman pada seorang wanita Muslimah dan tidak ditanggapi dengan tangan terulur menjadi marah besar karena menganggap dirinya disepelekan. Bisa jadi ada lelaki yang "Islam KTP" menggerutu habis-habisan karena ketika menghadiri resepsi perkawinan dipisahkan duduknya dari isterinya yang harus duduk sekelompok dengan kaum wanita, ia duduk berbanjar sesama lelaki. Bisa juga ada orang yang menggerutu habis-habisan karena harus makan minum sambil berdiri dalam respsi "standing party" yang dianggapnya melanggar ajaran agama. "Teachers must develop an awareness of how ethnic background affects actions." (Berns, 2004:223; cetak tebal dari Penulis).

Jadi, tampak bahwa agar pendidikan multikultural bisa berjalan sesuai dengan "rel' Indonesia, maka berbagai penelitian antropologis-sosiologis untuk pendidikan perlu digalakkan. Hasil-hasil penelitian tersebut akan menjadi "pendekatan operasional" dalam melaksanakan pendidikan di sekolah, secara nasional di seluruh Indonesia, bahkan untuk pergaulan sehari-hari, konstekstual, di tingkat lokal.

Muatan pendidikan IPS, dengan demikian, akan lebih kaya, bukan hanya kulit luar pelajaran multikultur Indonesia berupa tarian, nyanyian, makanan, adat-istiadat, rumah adat, pakaian dan sejenisnya, melainkan jauh merasuk sampai ke akar-akar budayanya. Demikian pula halnya dengan pendidikan kewarganegaraa $(\mathrm{PKn})$, akan lebih diperkaya lagi karena dengan pengenalan nilai budaya itu maka dapat lebih meningkatkan

...kesadaran akan kehidupan yang beranekaragam sebagai sunnatullah. Kesadaran ini amat dibutuhkan, karena kalau sudah dihayati oleh setiap warga bangsa akan menimbulkan sifat tenggang rasa dan toleransi. Kesadaran ini tidak akan bisa muncul dengan sendirinya dengan baik, melainkan diperlukan rekayasa, yakni suatu upaya yang disadari dan direncanakan untuk mencapai suatu tujuan tertentu. Rekayasa tersebut bisa dilaksanakan lewat pendidikan formal sistem persekolahan, maupun lewat non- 
formal dalam bentuk kegiatan di lingkungan masyarakat yang melibatkan keluarga-keluarga (Zamroni, 2011a:115).

Penelitian sosiologis-antropologis nilai budaya serupa itu diperlukan pula untuk tingkat daerah dan lokal yang memiliki penduduk dari beragam suku bangsa dan atau multikultur, bukan saja sekedar untuk menumbuhkan rasa dan sikap menghargai, mengakui, dan toleransi, melainkan juga untuk prevensi terjadinya konflik kultural dan "prejudice" di lapanganberbasis kearifan lokal. Guru-guru dan administrator sekolah, sukur-sukur dosen perguruan tinggi terdekat, diharapkan intensif melakukan penelitian sosiologis-antropologis seperti itu, sesederhana apapun caranya, tidak harus seperti penelitian ilmiah disertasi. Untuk itu tentu diperlukan juga ada dana khusus (dana hibah penelitian) dari Pemerintah. Konflikkonflik yang seolah terjadi antar ras, etnis, atau kultur dan agama, tentu harus ditelusur akar penyebabnya dengan cermat dan jujur. Kelokalan pengetahuan (local wisdom) sangat diperlukan untuk kasus-kasus antar budaya kedaerahan atau kasus-kasus setempat lainnya.

\section{SIMPULAN}

1. Gerakan pendidikan multikultural di Amerika Serikat-yang kemudian mendunia-dilandasi adanya diskriminasi rasial, etnisitas, jender, dan budaya oleh kelompok (etnis) dan budaya "mayoritas" White Male Protestant Anglo-Saxon (WMPA), dan karenanya berupaya agar seluruh warga Amerika Serikat, tanpa kecuali, mendapatkan hak yang setara untuk mendapatkan pendidikan.

2. Masyarakat Amerika Serikat kental dengan warna ras, etnis, budaya, dan bahasa, dan karenanya sampai saat ini masih terjadi diskriminasi terhadap kelompok "minoritas non-WMPA" dan konflik antar kelompok tersebut.

3. Masyarakat dan bangsa Indonesia berbeda etnisitas dan budayanya. Kendati di Indonesia ada ras dan etnis serta budaya beragam, yang lebih menonjol adalah subetnis dan subkultur kedaerahan. Di sisi lain, budaya Indonesia lebih akomodatif sifatnya dibandingkan "dominatif," dan sebagian merupakan budaya yang "isolated" berada di daerahnya masing-masing, tidak terlampau intensif berhubungan dengan budaya lain, apalagi bersinggungan. Oleh karenanya pendidikan multikulutral yang dikembangkan di Amerika Serikat, manakala akan diterapkan di Indonesia harus dilakukan secara benar sesuai dengan hakikinya, dan secara bijaksana kontekstual berbasiskan realita budaya dan etnisitas yang ada di Indonesia, dengan memperhatikan pula "local wisdom" setempat.

4. Pendidikan multikultural di Indonesia lebih tepat dipandang sebagai pendekatan, yaitu pendekatan pendidikan yang mengupayakan agar nilai-nilai budaya kedaerahan (suku bangsa) dan agama di Indonesia dapat dipahami, dihargai, dan dimanfaatkan untuk kepentingan pendidikan kebangsaankewarganegaraan berlandaskan semboyan "bhinneka tunggal ika" dan falsafah Pancasila, dengan mengedepankan toleransi dan kerukunan antar budaya dan pemeluk agama.

5. Penelitian-penelitian sosiologis-antropologis yang menggali nilai-nilai budaya Indonesia untuk pendidikan perlu digalakkan, agar 
muatan isi pendidikan kewarganegaraan (lewat PKn), pendidikan IPS, dan agama, serta pendidikan untuk calon pendidik, memuat pula nilai-nilai budaya, mencakup etiket atau tatakrama sopan-santun budaya dan agama Indonesia yang beragam.

6. Penelitian serupa di tingkat daerah dan lolal diperlukan pula untuk mengembangkan kearifan lokal dalam mengembangkan sikap tenggang rasa, saling menghargai, kerukunan, dan toleransi, demi keutuhan kebangsaan Indonesia menuju masyarakat adil dan makmur (berbarkat) yang bahagia dunia akhirat, serta mencegah terjadinya konflik antar budaya, agama, atau suku di daerah setempat.

\section{DAFTAR PUSTAKA}

Banks, James A. (2002). An introduction to multicultural education. Boston: Allyn and Bacon.

Banks, James A. (2007). Educating citizens in a multicultural society. New York: Teachers College Columbia University.

Berns, Roberta M. (2004). Child, family, school, community:Socialization and support. Belmont: Thomson Wadsworth.

Gollnick, Donna M, and Chinn, Philip C. (2006). Multicultural education in a pluralistic society. Upper Saddle River: Pearson Merril Prentice Hall.
Gorski, Paul C. (2010). "The challenge of defining 'multicultural education'." Diakses Desember 2011 dari www.edchange.org/multicultural/initial. $\underline{\text { html. }}$

Majlis Luhur Persatuan Taman Siswa. (1977). Karya Ki Hadjar Dewantara. Bagian pertama: Pendidikan. Yogyakarta: Majlis Luhur Persatuan Taman Siswa.

National Associaton for Multicultural Education (NAME). (2003). "Multicultural education definition." Diakses Desember 2011 dari http://www.nameorg.org/

Noel, Jana. Ed. (2000). Sources: Notable selection in multicultural education. Guilford: Duskin/McGraw-Hill.

Reissman, Rose. (1994). Evolving multicultural classroom. Alexandria: Association for Supervision and Curriculum Development.

shareforearth.blogspot.com/2011/01

Sunarto, Kamanto, Heng, Russel Hiang-Khng, Saifuddin, Achmad F. (2004). Multicultural education in Indonesia and Southeast Asia. Depok: Jurnal Antropologi Indonesia.

www.worldbank.org/afr/ik/basic.

Zamroni. (2010). "The implementation of multicultural education: A Reader." Yogyakarta: Graduate Program, the State University of Yogyakarta.

Zamroni. (2011a). Pendidikan demokrasi pada masyarakat multikultural. Yogyakarta: Gavin Kalam Utama.

Zamroni. (2011b). "Researh on Multicultural Education: A Reader." Yogyakarta: Graduate Program, the State University of Yogyakarta. 